\title{
OPEN The in-utero experience of piglets born from sows with lameness shapes their life trajectory
}

\author{
Marisol Parada Sarmiento ${ }^{1,2 凶}$, Thiago Bernardino ${ }^{1}$, Patricia Tatemoto ${ }^{1}$, Gina Polo ${ }^{3}$ \& \\ Adroaldo José Zanella ${ }^{1 凶}$
}

Experiences during gestation can alter the mother's behavior and physiology, thereby potentially affecting the behavioral and physiological development of the offspring. In livestock, one common challenge for pregnant animals is lameness: a multifactorial condition that causes pain, stress, resulting in poor welfare outcomes. Since maternal pain can affect offspring development, we aimed to quantify the behavioral response in 142 piglets born from sows with different degrees of lameness during pregnancy. Gait scores of 22 pregnant group-housed sows were assessed six times at 2-week intervals. Lameness scores varied from 0 (no lameness) to 5 (most severe lameness score). Saliva samples and behavior were assessed in the sows throughout pregnancy. Sows were moved to individual farrowing pens and placental tissue was collected for glucocorticoid assessment. At 28 days of age, piglets were weaned, weighed, and regrouped by body size and sex. Skin lesions were counted for each piglet on days 28,29 , and 30 after birth. During open field and novel object tests on day 30 , the vocalization and activity levels were evaluated. Piglet data were grouped by the lameness score of the sows as G1 (without lameness), G2 (moderate lameness), and G3 (severe lameness). Data analysis included ANOVA or Kruskal-Wallis tests and pairwise comparisons which were performed using Tukey and Kramer (Nemenyi) test with Tukey-Dist approximation for independent samples. G2 piglets were heavier than $\mathrm{G} 3$ at weaning. $\mathrm{G} 1$ piglets had fewer skin lesions at days 28 and 29 than G2 piglets. Moreover, $\mathrm{G} 1$ piglets vocalized more than $\mathrm{G} 2$ when they were subjected to the combined open field and novel object test. We did not identify differences among sows showing different lameness scores in the concentration of placental or salivary glucocorticoids. Lameness in pregnant sows altered the offspring's weight gain, number of skin lesions and vocalizations, together showing evidence that lameness in sows affect offspring performance and behavior.

Lameness in pregnant sows is a common and painful condition and is one of the most frequent reasons for culling, causing considerable economic losses ${ }^{1,2}$. It is also recognized as a very important indicator of animal welfare $^{3}$. Lameness can be the consequence of several factors including inadequate handling, improper housing conditions, and deficient nutrition. High sow density and poor flooring conditions can trigger lameness which can be exacerbated by post-mixing aggression ${ }^{4}$. Furthermore, nutritional factors such as mineral and vitamin deficiencies may be detrimental to bones, articular cartilages, and claws ${ }^{5}$. Lameness can cause health, behavioral, and physiological alterations in animals. The main health impairments associated with lameness in sows include traumas, fractures, osteochondrosis, and foot lesions ${ }^{1}$. Behavioral modifications involve a decrease in social interactions, exploratory behavior ${ }^{6}$, and alterations in feeding and lying behavior ${ }^{7,8}$.

The behavioral changes associated with lameness indicate that the condition causes pain ${ }^{6,9,10}$. Objective assessment of lameness is established using scoring systems based on behavioral changes, caused by pain, that can distinguish levels of severity ${ }^{11}$. According to the International Association for the Study of Pain (IASP), pain can be defined as an unpleasant sensory and emotional experience associated with actual or potential tissue damage $^{12}$. Physiological responses to painful stimuli can be measured by changes, which are mostly mediated by the sympathetic nervous system and by the hypothalamic-pituitary-adrenal axis (HPA). Measurement of

\footnotetext{
${ }^{1}$ Center for Comparative Studies in Sustainability, Health and Welfare, Department of Preventive Veterinary Medicine and Animal Health, School of Veterinary Medicine and Animal Science, University of São Paulo, Campus Fernando Costa, Av. Duque de Caxias Norte, 225 Caixa Postal 23, Pirassununga, SP CEP 13635-900, Brazil. ${ }^{2}$ Faculty of Veterinary Medicine, University of Teramo, Piano d'Accio, 64100 Teramo, Italy. ${ }^{3}$ Grupo de Investigación en Epidemiología y Salud Pública, Universidad de La Salle, Bogotá, Colombia. ${ }^{\circledR}$ email: mparadasarmiento@unite.it; adroaldo.zanella@usp.br
} 
catecholamines and changes in autonomic responses, such as respiratory rate, heart rate, blood pressure and body temperature, are indicators of sympathetic system activation. Measures usually used to assess HPA responses, such as production of glucocorticoids ${ }^{13}$ are reported in animals experiencing pain. Painful stimuli also leave traces at the molecular level, altering inflammatory markers such as TNFa, C-reactive protein, and several interleukins ${ }^{14}$. Since pain is challenging and can be stressful, this scenario can worsen welfare outcomes in pregnant animals due to physiological and molecular responses that could result in epigenetic changes affecting offspring developmental outcomes. Studies have shown that stress or inflammatory responses during pregnancy alters the development of brain structures in the offspring, mainly those pathways responsible for memory, social behavior and emotions ${ }^{15,16}$.

Glucocorticoids play a fundamental role during pregnancy in the normal development of fetal organs. Glucocorticoid increase as a result of adverse situations in pregnant subjects can impact fetal development affecting mainly the hippocampus, HPA axis functions and behavior ${ }^{16,17}$. The main placental protective system against active and high glucocorticoid levels is the placental enzyme 11 beta-hydroxysteroid dehydrogenase (11 $\beta$-HSD2 ), responsible for the inactivation of cortisol by conversion to cortisone. A failure in this system has negative consequences in fetal programming ${ }^{18}$.

It has been reported that a balance between embryotrophic and embryotoxic cytokines in the female reproductive tract is determined by several stressful events, impacting embryo implantation, placental development, and fetal growth. These mediate biological effects of embryo programming, embryo plasticity, and adaptation ${ }^{19,20}$. In a gene expression study using mononuclear cells from cows with and without lameness an up-regulation of the GM-CSF-R-alpha gene in lame relative to sound cows was reported ${ }^{21}$. In another study the cytokine GM-CSF was identified as a physiological regulator of fetal growth trajectory and placental morphogenesis ${ }^{22}$.

Painful conditions during pregnancy are sources of prenatal stress, which involve a cascade of physiological and molecular responses with potential to reprogram epigenetically genes involved in the development of stress neurocircuitry in the offspring, producing phenotypic modifications such as increased basal glucocorticoid levels, decreased expression of glucocorticoid receptors in the hippocampus and changes in spatial learning or in memory performance ${ }^{23}$.

Lameness is a painful and stressful condition for the sow which has the potential to affect fetal development, the changes being mediated by high glucocorticoid concentration, cytokines and other stress biomarkers that could cause epigenetic changes.

Given the impact of maternal pain in modulating coping systems in the offspring brain ${ }^{24}$, we aimed to measure developmental outcomes in piglets born from sound and lame sows. We hypothesized that offspring born from sows with lameness during pregnancy would show changes in fear responses to novel situations, and also in aggressive behavior, which can, in turn, affect performance outcomes. Specifically, we hypothesized that during an open field and novel object test, piglets from lame sows would explore the arena less and would show longer latency to explore a novel object when compared with offspring of non-lame sows. Furthermore, we hypothesized that piglets from sows without lameness would cope better with social conflicts, thus having fewer skin lesions when compared with piglets born from lame sows.

\section{Materials and methods}

Ethical approval. Data were collected from the experimental pig farm of the University of São Paulo (USP), located at the Campus Fernando Costa-Pirassununga, Brazil, with the approval of the Ethics Committee on the Use of Animals (CEUA) of the School of Veterinary and Animal Science (FMVZ/USP), with the number $\mathrm{N}^{\circ}$ 3606300114, according to the Law 11.794, of October 8, 2008 and Decree 6899 of July 15, 2009 with the rules issued by the National Council for Control of Animal Experimentation (CONCEA) - Brazil. The study was carried out according to the ARRIVE guidelines (https://arriveguidelines.org/). The approval of the ethics committee is placed as Supplementary Information.

Animals, facilities, and handling. The present data were collected during a concomitant experiment which measured the impact of fiber in the diet of gestating sows on their offspring ${ }^{25}$.

Data from 22 pregnant sows (F1 Landrace $\times$ Large White) and their offspring were studied. The sows were nulliparous and healthy at selection, and subsequently inseminated in the same period of the year with pooled semen from a specified group of boars. After insemination and until day 107 of gestation, sows were housed groups of nine in pens that measured $6.7 \mathrm{~m} \times 4.4 \mathrm{~m}\left(3.3 \mathrm{~m}^{2}\right.$ per sow). Each group was fed in nine individual feeding stalls $(1.8 \mathrm{~m} \times 0.55 \mathrm{~m})$ two times per day-morning and afternoon-and water was supplied ad libitum through nipple drinkers. Individual food consumption was measured only during gestation, not during lactation.

On day 107 of gestation, the sows were moved from the group pens to individual farrowing pens measuring $4.3 \mathrm{~m} \times 2 \mathrm{~m}$. Connected to the pen, there was a creep-feeding area made of concrete $(0.97 \mathrm{~m} \times 2.2 \mathrm{~m})$, where piglets had unlimited access to solid feed from birth. We kept all animals in the farrowing pens until day 28 of lactation. Bedding material was provided for the sows and piglets, composed of dehydrated sugarcane bagasse and hay. Farrowing was monitored with IP video cameras (FOSCAM, Fi9821p HD 720P), with a real-time internet transmission to the experimenters. Farrowing was followed through computers, smartphones, and direct observation. All sows were fed an identical solid lactation diet with ad libitum access.

All piglets were weighed on the 1st, 21st, and 27th days of age. In addition, during the first day of life, routine management tasks of the farm were carried out: teeth grinding, administration of iron dextran (100 mg, intramuscular), and identification by an ear notch under local anesthesia with $5 \%$ lidocaine cream. Weaning occurred at 28 days of age and the piglets were moved to experimental pens $(1 \mathrm{~m} \times 0.75 \mathrm{~m})$ with slatted plastic floors. Weaned piglets were mixed into groups formed from two different litters, allocating four piglets matched 


\begin{tabular}{|l|l|}
\hline Degree of lameness & Description \\
\hline 0 & The animal moves easily with little stimulation and bears weight comfortably of all its legs \\
\hline 1 & Minor alterations in the gait. When standing, the sow alternates weight bearing in legs. It still walks easily \\
\hline 2 & $\begin{array}{l}\text { Locomotor disturbance is perceptible in the gait, shorting the steps. Alters position and support of the legs when } \\
\text { standing }\end{array}$ \\
\hline 3 & Supports the limb with difficulty. Shortened stride. Reluctant to bear weight on the affected limb \\
\hline 4 & $\begin{array}{l}\text { Lameness of one or more limbs, display of compensatory behaviors such as arching of the back and/or squatting of } \\
\text { the head. Reluctance to walk, difficult to move from one place to another }\end{array}$ \\
\hline 5 & Try to lie down, get up with difficulty and try not to support the committed leg(s) \\
\hline
\end{tabular}

Table 1. Locomotion score system to assess gait in sows . adapted from Refs. ${ }^{26,27}$.

\begin{tabular}{|l|l|}
\hline Behavior & Definition \\
\hline Sleeping & Sleeping animal \\
\hline Lying ventrally & Lying with belly facing the ground with all limbs under the body \\
\hline Lying laterally & Lying sideways, with all the limbs extended laterally \\
\hline Standing & Body supported by the four limbs \\
\hline Shame-chewing & Continuous chewing without the presence of visible food in the oral cavity \\
\hline Rooting the floor & Snout touches the ground followed by head movements \\
\hline Rooting on the empty feeder & Snout touches the empty feeder followed by head movements \\
\hline Licking the floor & The tongue touches the floor and is followed by movements with the head \\
\hline Interacting with mats & Snout or tongue touches mats followed by head movements \\
\hline Interacting with fences or gate & Biting or nibbling the fence wire or gate \\
\hline
\end{tabular}

Table 2. Sows behaviors collected on first, second and last third of gestation, before and after feeding. . Adapted from Ref. ${ }^{31}$.

by weight and sex per pen (for more details see Bernardino et al. ${ }^{25}$ ). Food and water were provided ad libitum, and the pen was cleaned daily.

Experimental design. To assess the effects on the offspring of lameness during gestation, we assessed lameness scoring 22 sows, six times throughout gestation ${ }^{26,27}$. The behaviors of sows, salivary, and placental glucocorticoid concentration were analyzed ${ }^{28}$. In the offspring $(\mathrm{N}=156$ piglets), aggressiveness was assessed indirectly by counting skin lesions $s^{25,29}$ and behavior was assessed with a combination of open field and novel object tests ${ }^{30}$. An explanation of the experimental design can be seen in Supplementary Fig. S1.

Lameness assessment in sows. During gestation, six lameness assessments were performed with intervals of 2 weeks between measures. The lameness score applied was a combination of two validated score systems (Table 1$)^{26,27}$.

According to the lameness score, sows were classified into three groups, G1: Sows with a degree of lameness $\leq 1$ in all six lameness assessments. G2: Sows with a degree of lameness $\leq 3$, with at least one of the six lameness assessments with degree 2 or 3. G3: Sows with a degree of lameness $\leq 5$, with at least one of the six lameness assessments with degree 4 or 5 .

When lameness was detected, pain treatment was performed according to a standard procedure; Flunixin Meglumine at $2.2 \mathrm{mg} / \mathrm{kg}$ was administrated intramuscularly, once a day, for 4 days to sows with locomotion score $\geq 3$.

Pregnancy and farrowing. During pregnancy behaviors related to position and activity were collected on days $29,30,31,59,60,61,74,75,76,89,90$, and 91 , in four periods per day: before and after feeding in the morning, and before and after feeding in the afternoon. During each period, each animal was observed three times, each lasting $2 \mathrm{~min}$, for a total of $6 \mathrm{~min}$ per period and $24 \mathrm{~min}$ per day of observation. The behaviors observed were sleeping, lying ventrally, lying laterally, standing, sham-chewing, rooting the floor, rooting on the empty feeder, licking the floor, interacting with mats, and interacting with fences or gates. The details of each behavior are in Table 2.

Saliva samples were collected on the same days that behavioral assessment was carried out, early in the morning (06:00) and in the late afternoon (18:00). These samples were stored at $-20^{\circ} \mathrm{C}$ immediately after collection and cortisol was measured with Enzyme Immunoassay (EIA) ${ }^{32}$. The collection methodology used was adapted from Refs. ${ }^{33,34}$, using two hydrophilic cotton rolls tied to a dental floss with long tips and presented to each animal.

After farrowing, four placenta samples of the same size were collected from random locations from 19 sows and stored immediately at $-20^{\circ} \mathrm{C}$. Glucocorticoid extraction was performed to measure cortisol and cortisone levels using an $\mathrm{EIA}^{32}$. The placentas of three sows were not collected due to unforeseen problems. 


\begin{tabular}{|l|l|l|l|}
\hline Group & Degree of lameness & Number of sows & Number of piglets \\
\hline G1 & $0-1$ & 7 & 52 \\
\hline G2 & $2-3$ & 10 & 66 \\
\hline G3 & $4-5$ & 5 & 38 \\
\hline Total & - & 22 & 156 \\
\hline
\end{tabular}

Table 3. The number ( $\mathrm{n})$ of sows and piglets studied per group.

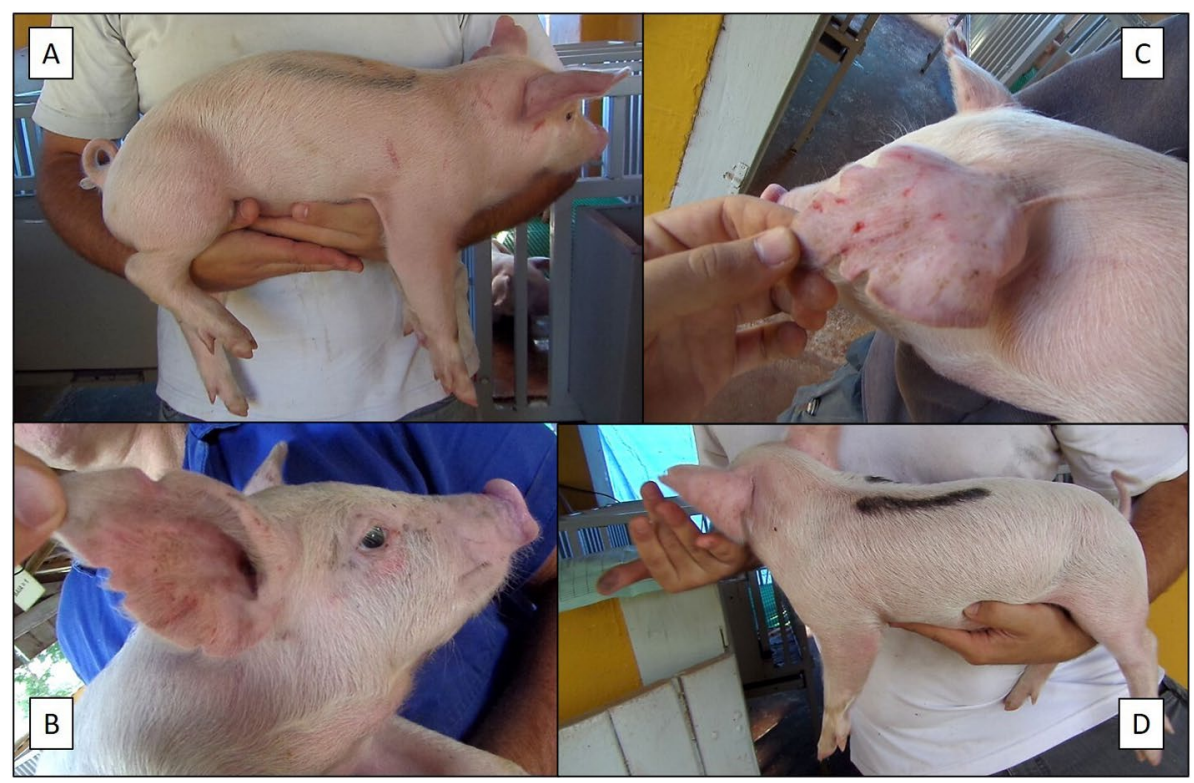

Figure 1. Examples of images used to count skin lesions. (A) Right lateral body; (B) face and right lateral ear; (C) back of the left ear and (D) left lateral body.

Additional data collected, included pregnancy length, the total number of piglets born, total piglets born alive, total litter weight at farrowing, total litter weight at 21 and 27 days of age, average daily litter weight gain, average daily weight gain per animal and number of crushed piglets.

Post-mixing aggression score. Data from 156 piglets from the 22 sows were collected and analyzed according to the score of lameness measured in the sow. The number and distribution of the individuals in each group are shown in Table 3.

Pre- and post-mixing aggression was assessed, based on validated methodology $y^{25,29}$. Photographs and videos of each piglet were taken daily at 28,29, and 30 days of age (see Fig. 1). Six piglets from each sow (three males and three females) were used for the evaluation of skin lesions. Two independent evaluators, blind to the treatments, counted skin lesions using the photographs and videos.

Open field and novel object test. A combination of open field and novel object tests were performed on 142 piglets at the end of the experiment, when pigs were 30 days of age using the methodology previously described ${ }^{30}$ to assess activity levels, exploratory behavior, and vocalizations (Table 4 ). The tests were carried out in a pen with the floor marked with squares (see Fig. 2). To carry out the tests, the piglets were taken randomly, alternating between males and females. Due to unforeseen difficulties, the tests could not be done on all piglets; only 142, out of the 156 piglets, were assessed in both tests.

The open-field test consisted of positioning each piglet at the same starting point in the pen, in order to assess the time taken to move, time spent walking, and time remaining in peripheral or central squares. Immediately following the open field test, the novel object test was carried out, and involved introducing an unknown object into the pen to assess latency, exploratory behavior, and proximity to the object. A yellow empty polypropylene bucket with a capacity of $20 \mathrm{~L}$ was used as an unknown object. To avoid visual contact between the piglets and the experimenter, a pulley mechanism was used to introduce the bucket in the pen. In both tests, all types of vocalization were counted. For each individual the tests lasted $10 \mathrm{~min}: 5 \mathrm{~min}$ for the open field test followed by $5 \mathrm{~min}$ for the novel object test. To reduce the possible chemical signals present in the environment, the pen was always washed with water prior to each piglet assessment. 


\begin{tabular}{|c|c|c|}
\hline Test & Measure & Description \\
\hline \multirow{4}{*}{ Open field test } & Latency & Time in seconds between piglet entering in the pen and walking \\
\hline & Activity & Time in seconds spent walking \\
\hline & Quadrants accessed & Time in seconds spent in central and lateral quadrants (quadrants on the edge of the pen) \\
\hline & Vocalizations & A count of all types of vocalization \\
\hline \multirow{4}{*}{ Novel object test } & Latency & $\begin{array}{l}\text { Time in seconds between the bucket being placed in the pen until animal interaction with the object (close to and with the head toward to } \\
\text { the object) }\end{array}$ \\
\hline & Near to the object & Time in seconds the animal spent close to the object (in quadrants that surround the object) \\
\hline & Quadrants accessed & Time in seconds spent in central and lateral quadrants (quadrants on the edge of the pen) \\
\hline & Vocalizations & Number of all types of vocalizations \\
\hline
\end{tabular}

Table 4. Description of data collected during open field and novel object test.

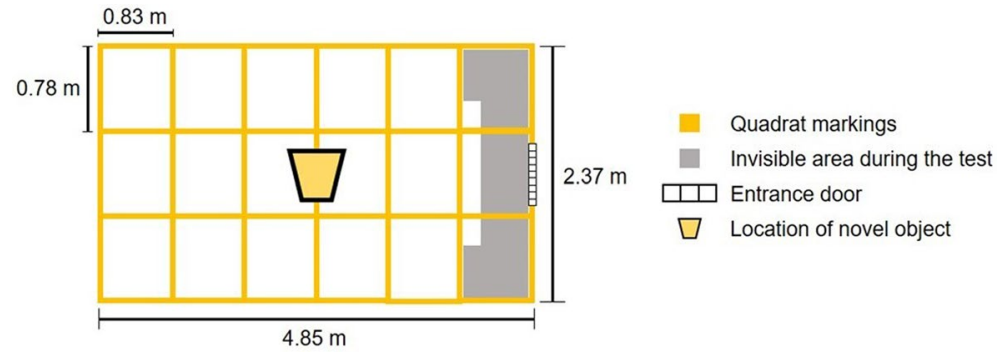

Figure 2. Graphic representation of pen used to perform the open field and novel object tests.

Open field and novel object tests were recorded with a digital camera (Samsung WB250F Smart Wi-Fi Digital).

Statistical analysis. Multiple correspondence analysis (MCA), a type of multivariate analysis, was employed to construct relationships among piglets variables (weight at birth, skin lesions, latency/vocalizations in the open field test, latency/vocalizations/exploration in the novel object test) or sows variables (born piglets, alive born piglets, average weight at birth, average daily weight gain, sow weight, salivary cortisol ratio at pregnancy, placental cortisone and cortisol concentration), the presence of high/low fiber diet of sows (used in the first experiment ${ }^{25}$ ) and its association with the different lameness groups. The associations were confirmed using a Chi-square test.

To determine the residual distribution was used Shapiro-Wilk test with all variables, when the result was $<0.05$ a non-parametric test was used, and when it was $>0.05$ a parametric test was used, always considering the number of groups to be compared. The variables used to perform a Shapiro Wilk test were in sows: performance data, ratio between morning/afternoon saliva cortisol concentration and placental cortisol/cortisone concentrations; in piglets: skin lesions number, weight at birth, 21 and 27 days of age, open field, and novel object tests data.

To analyze saliva cortisol at 75 and 90 days of pregnancy, we calculated the ratio between morning and afternoon of each day, ratio was calculated dividing morning cortisol concentration into afternoon cortisol concentration. Subsequently, a Kruskal-Wallis test was used to compare the ratio between groups. Placental cortisol and cortisone were examined in an intraspecific and interspecific way.

Intraspecifically, a T-test was performed, comparing placental cortisol with placental cortisone from the same group. Interspecifically a One-way ANOVA was performed, comparing placental cortisol or placental cortisone from different groups. We calculated the ratio between placental cortisol and cortisone from each sow, dividing cortisol concentration into cortisone concentration and subsequently a One-way ANOVA was performed to compare it between groups.

Weight and skin lesions were compared independently for each day between groups using Kruskal-Wallis test or ANOVA.

A significance level of 5\% was considered. All analyses and graphs were performed using the free software environment for statistical computing $\mathrm{R}$ ( $\mathrm{R}$ version 4.0.5) ${ }^{35}$. The MCA was performed using the $\mathrm{R}$ packages "FactoMineR"36 and "factoextra"17. To calculate Pairwise Multiple Comparisons of Mean Rank Sums Extended was used the package "PMCMRplus" ${ }^{13}$.

\section{Results}

After performing an MCA and confirming it with a Chi-square, no associations were found between previous nutritional treatments in sows and the results of the current study (Chi-squared test, p-value =0.31; see Supplementary Figs. S2, S3 for details). 


\begin{tabular}{|c|c|c|c|c|c|c|c|c|c|}
\hline \multirow[b]{2}{*}{ Variable } & \multirow[b]{2}{*}{ Age days } & \multirow[b]{2}{*}{ Test } & \multicolumn{3}{|l|}{ Mean } & \multirow[b]{2}{*}{ p-value } & \multicolumn{3}{|c|}{ Post-hoc p-value } \\
\hline & & & G1 & G2 & G3 & & G1-G2 & G1-G3 & G2-G3 \\
\hline Weight (kg) & 27 & \multirow{3}{*}{ Kruskal-Wallis } & 8.00 & 8.45 & 7.95 & 0.022 & 0.08 & 0.93 & 0.04 \\
\hline \multirow{2}{*}{ Skin lesions } & 28 & & 2.69 & 5.08 & 2.95 & 0.003 & 0.01 & 0.99 & 0.02 \\
\hline & 29 & & 24.79 & 32.49 & 30.58 & 0.026 & 0.02 & 0.26 & 0.70 \\
\hline Open field test vocalizations & \multirow{2}{*}{30} & ANOVA One way & 219 & 170 & 183 & 0.044 & 0.04 & 0.35 & 1.00 \\
\hline Novel object test vocalizations & & Kruskal-Wallis & 221 & 160 & 178 & 0.002 & 0.001 & 0.12 & 0.51 \\
\hline
\end{tabular}

Table 5. Significant results of weight, number of skin lesions and number of vocalizations during open field and novel object test. The post-hoc test used to ANOVA One way was a Tukey and for Kruskal-Wallis was a Nemenyi test. Degrees of freedom always were 2.

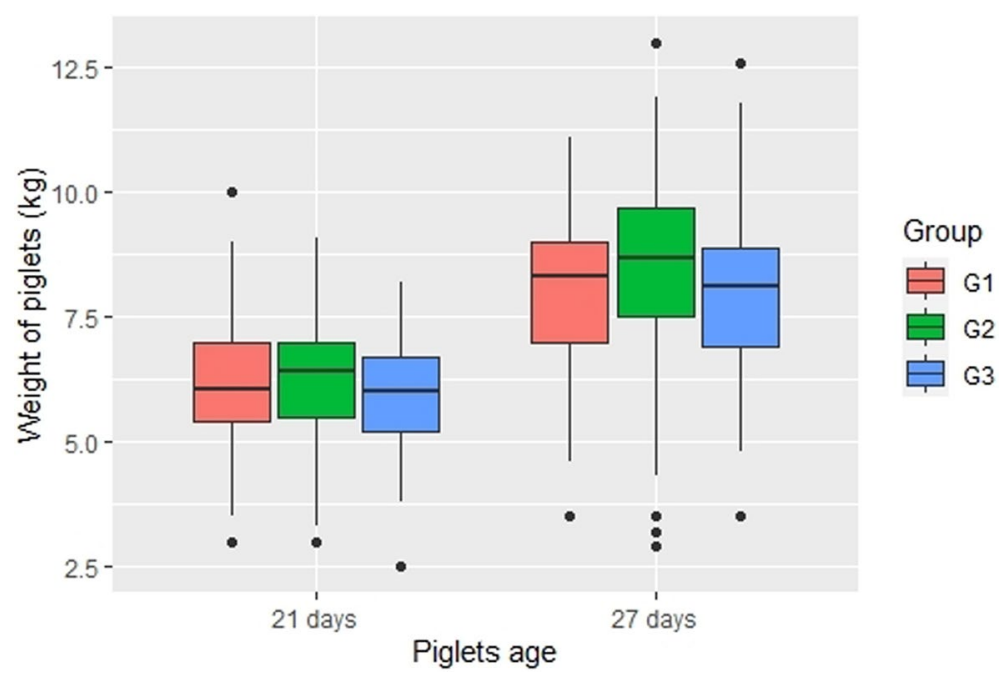

Figure 3. Boxplots to represent the weight of individual piglets at 21 and 27 days of age divided in three groups, according to sow lameness score (G1: lameness score 0-1; G2: lameness score 2-3; G3: lameness score 4-5). This figure was performed in the programming language $\mathrm{R}$ using the package ggplot $2^{35}$.

Data from sows and offspring before weaning. Descriptive measures of saliva cortisol, placental cortisol/cortisone, and performance data can be found in Supplementary Tables S1, S2, and S3, respectively.

On day 75 and 90 of pregnancy, we did not find differences between lame and non-lame sows when comparing salivary cortisol ratios (Kruskal-Wallis test; $\mathrm{p}>0.05$ ).

No difference was found in placental cortisol and cortisone concentration between G1, G2, or G3 (One-way ANOVA test; $\mathrm{p}=0.681$ for placental cortisol, and $\mathrm{p}=0.457$ for placental cortisone), and when comparing placental cortisol with placental cortisone in each group, concentration of cortisone was always higher than cortisol (T-test; $\mathrm{p}$-value $\leq 0.05$; see Supplementary Table S2 for details). We did not find differences when comparing placental cortisol/cortisone ratios between sow groups (One-way ANOVA; $\mathrm{p}>0.05$ ). The results of performance data showed no differences when comparison was carried out between groups G1, G2, and G3 ( $p>0.05$ ).

Body weight and skin lesions in piglets. We did not identify any weight difference at birth or at 21 days of age between piglets from groups G1, G2, or G3. However, weight at 27 days old was different between the groups (Kruskal-Wallis test; $\mathrm{p}=0.02$ ), with G3 piglets being lighter than G2 piglets (see Table 5 for details). A box plot of the weight of the piglets at 21 and 27 days old can be found in Fig. 3 (see Table 5 for details).

Regarding the number of skin lesions, we found differences at day 28 and 29 (Kruskal-Wallis test; $p<0.05$; see Table 5 for details). The Fig. 4 is a box plot of the number of skin lesions of the piglets at 28 and 29 days of age. On day 28, piglets from group G1 had fewer skin lesions than piglets from G2, and piglets from G3 had fewer skin lesions than piglets from G2 (see Table 5 for details). Additionally, we did not find differences between piglets from group G1 and G3. On day 29 after farrowing, we identified fewer skin lesions in piglets from group G1 when compared with piglets from G2 and no difference in the remaining comparisons (see Table 5 for details). On day 30 , no difference was found between groups.

Descriptions of weight and skin lesion measures can be found in Supplementary Table S4.

Open field and novel object test. In the open field test, we did not identify differences in latency (Kruskal-Wallis test; $\mathrm{p}=0.751$ ), activity (One-way ANOVA test; $\mathrm{p}=0.823$ ), access to peripheral (Kruskal-Wallis test; $\mathrm{p}=0.931$ ) or central quadrants (One-way ANOVA test; $\mathrm{p}=0.374$ ). However, the number of vocalizations 


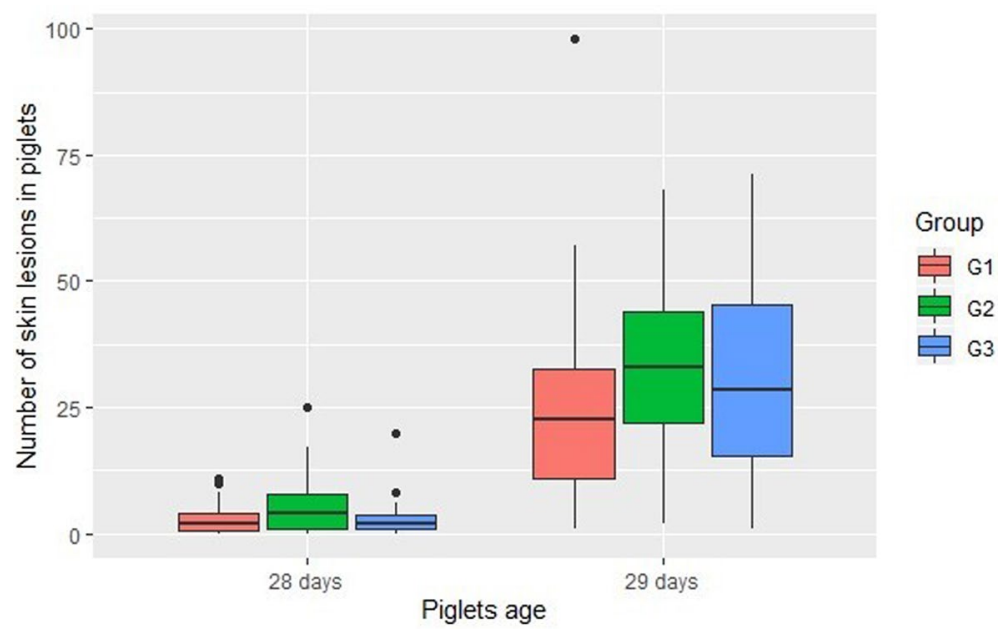

Figure 4. Number of skin lesions in piglets with 28 and 29 days of age, divided in three groups, according to sow lameness score (G1: lameness score 0-1; G2: lameness score 2-3; G3: lameness score 4-5). This figure was performed in the programming language $\mathrm{R}$ using the package ggplot $2^{35}$.

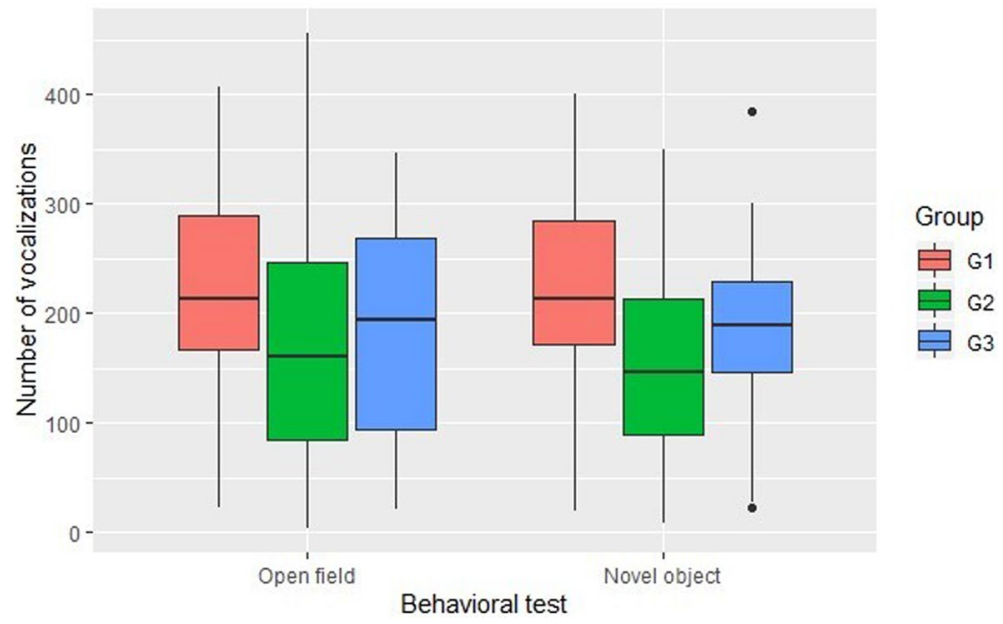

Figure 5. Number of piglet vocalizations during the open field and novel object test, divided in three groups, according to sow lameness score (G1: lameness score 0-1; G2: lameness score 2-3; G3: lameness score 4-5). This figure was performed in the programming language $\mathrm{R}$ using the package ggplot $2^{35}$.

was higher in piglets from group G1 (offspring of non-lame sows) compared with G2 (One-way ANOVA test; $\mathrm{p}<0.05$; see Table 5 and Fig. 5 for details), G3 was positioned between them without differing from either G1 nor G3.

Similar to the results of the open field test, we found that only the number of vocalizations differed in the novel object test, with a higher number of vocalizations recorded in piglets from group G1 compared with G2 (Kruskal-Wallis test; $\mathrm{p}<0.005$; see Table 5 and Fig. 5 for details), while G3 had fewer vocalizations than G1 but more than G2, without significant differences. We did not see a difference in latency (Kruskal-Wallis test; $\mathrm{p}=0.884$ ), object exploration (Kruskal-Wallis test; $\mathrm{p}=0.641$ ), or proximity to the novel object (Kruskal-Wallis test; $\mathrm{p}=0.254$ ).

Descriptive measures from the variables analyzed during open field and novel object test can be found in Supplementary Table S5.

\section{Discussion}

In this study, we have tested the hypothesis that the offspring born from sows with lameness, a painful condition experienced during pregnancy, are affected by their in-utero or neonatal experience. Here we showed that lameness, especially moderate lameness, in pregnant sows has effects on their offspring, increasing number of skin lesions, affecting weight at weaning and vocalizations during open field and novel object tests. The inconsistency of the responses observed, which did not show graded effects with the severity of the lameness, could 
be associated with the treatment option that our ethical review board requested, and we promptly applied to the affected animals. The use of flunixin meglumine as an analgesic treatment could potentially have mitigated the negative impact of pain on severely lame sows. Even considering the impact of the therapeutic interventions on the study, we could not let severely lame animals without treatment, for ethical reasons. The administration of flunixin meglumine, in healthy pregnant sows, as a potential control, would be of limited use, given the complex nature of the inflammatory processes associated with lameness.

Surprisingly, there were no differences in glucocorticoid concentrations in saliva or placenta among the groups indicating that other mechanisms may be associated with the reported changes in the offspring.

It has already been reported in several species that an inadequate function of the enzyme $11 \beta-\mathrm{HSD}-2$ or high glucocorticoid concentrations during pregnancy could decrease the weight and size of the offspring ${ }^{39-42}$. According to the results obtained from the analysis of cortisol and cortisone concentration in the placenta, the absence of difference between the sow groups (G1, G2, and G3) showed no evidence of the role of glucocorticoid-mediated maternal stress. We anticipate that sows had effective action of the enzyme $11 \beta-\mathrm{HSD}-2^{18}$, or as the salivary cortisol data demonstrated, glucocorticoids were not the main mechanism responsible for the behavioral changes reported in this study. These findings suggests that other mechanisms could be responsible for the changes found in the offspring of sows with lameness. This could be mediated by other mechanisms associated with longer term stress that have the potential to alter fetal development ${ }^{43}$, or the levels of embryo toxic cytokines present in inflammation events during pregnancy ${ }^{19}$.

We propose that since lameness is a chronic condition ${ }^{44}$, and it could affect inflammatory biomarkers ${ }^{45,46}$, they should be evaluated in future studies. Measurement of biomarkers of chronic stress could have given a more comprehensive view of the stress that lame sows experienced, as it has been reported in cows ${ }^{21}$.

Moderate lameness and severe lameness during pregnancy did not affect litter performance data before 27 days of age. In the case of prolificacy, lameness has not been reported as a relevant factor that alters reproductive variables such as the number of live piglets ${ }^{47}$. However, individual piglet weight at 27 days of age was different between groups, being significantly lower in piglets G3 compared to G2 and showing a similar tendency in comparisons with G1. This result could have several explanations from the standpoint of nutritional, behavioral, hormonal, or metabolic mechanisms. When nutrition is not ideal during pregnancy, the metabolism of the fetus can be altered during the neonatal period. In our experiment, sows were fed individually during pregnancy, which meant that no effect of lameness on the ability of the sow to compete for food could account for the lower piglet body weight at weaning ${ }^{25}$. Feeding regime during lactation was the same for all the sows, but consumption was not controlled so if lame sows consumed a lesser quantity of food, it could, potentially affect milk production ${ }^{48,49}$. The aspect of a possible difference in food consumption, together with increased lying behavior reported in lactating lame sows ${ }^{7}$, is a plausible alternative explanation for the reduced piglet weight at 27 days of age, in the offspring of lame sows. This does not involve the in-utero experience. Shoulder ulceration is common in lactating sows housed in farrowing stalls producing decrease in nursing frequency ${ }^{50}$. In our data, none of the sows showed shoulder ulcers, however we did not collect data on frequency of nursing. It is important to mention that the measures of lameness were collected during pregnancy and at the time of parturition they were resolved. Certainly, measures of nursing events, milk intake and milk quality would be important to characterize the nutritional impact of lameness on the offspring. Another explanation is that glucocorticoids or cytokines intervene in a catabolic way in growth processes ${ }^{51}$, and in previous studies, where individuals have been treated with glucocorticoids during pregnancy, it was found that their offspring had lower weight at birth ${ }^{52}$. In our study, we did not find evidence of a higher concentration of glucocorticoids generated by stress or pain in lame sows. In addition the proper functioning of the enzyme $11 \beta-\mathrm{HSD}-2$ might be also affected, allowing areater passage of glucocorticoids to the fetus without prior inactivation ${ }^{43,53}$. We did not measure glucocorticoids in placental tissue during pregnancy ${ }^{54}$, and our data on the relationship between placental cortisol and cortisone at farrowing suggest that the placenta was efficient in inactivating cortisol to cortisone, but it is important to mention that sows where moved from group housing to individual farrowing pens and as result the placental concentration of cortisol and cortisone may not reflect the events when they did show lameness. Other possibilities are that the metabolic costs associated with coping with lameness that could have compromised the offspring during the prenatal and early postnatal period. In humans, low weight at birth is associated with morbidity in adulthood ${ }^{55}$, which leaves us with an open research window to conduct experiments that monitor morbidity in animals born from females with a high or low degree of prenatal stress, especially lameness. The placental concentration of cytokines, which are released in response to inflammatory processes, during pregnancy appears to be higher in smaller piglets when compared with large animals ${ }^{56}$. More studies should be conducted to elucidate the causal mechanisms that may affect the performance of piglets.

As proposed in our hypothesis, a lower number of skin lesions was recorded in piglets from G1 than G2 on days 28 and 29 of age. This result indicates that piglets born from sows without lameness cope better with challenging social situations, probably avoiding agonistic interactions, when compared with the offspring from sows with moderate lameness. No differences were found relating to skin lesions involving piglets from sows with severe lameness, most likely due to the pain relief offered to this group of sows which probably attenuated the effects of severe lameness. Piglet aggression has been associated with compromised memory processes, resulting from the disruption of stress-responsive genes in prematurely weaned pigs ${ }^{57,58}$. We did not measure whether memory processes varied between $\mathrm{G} 1, \mathrm{G} 2$, and G3, piglets, but this would be interesting to explore.

Vocalization was more frequent in piglets from G1 for both open field and novel object tests. These tests are recognized as fear tests, because they impose on the animals a novel and open area, in social isolation, and also a novel object, so that conflicting motivations such as avoidance and exploratory behavior can be measured ${ }^{59}$. Vocalizations, according to their characteristics, are considered as an indicator of negative or positive emotions in different species, including domestic pigs ${ }^{60-63}$. In our results, the emotional valence is difficult to determine since we do not know the characteristics of the vocalizations. Vocalization in piglets could have a beneficial 
evolutionary role when exposed to social isolation or situations that represent a negative emotional valence ${ }^{64,65}$. Nevertheless, it would be worth comparing vocalizations in piglets exposed to fear tests in other contexts to make a better comparison, also adding analysis of the acoustic characteristics of these vocalizations, to better analyze associated emotions.

To our knowledge, this is the first study investigating the effects of lameness in sows during gestation on developmental outcomes in the offspring. Here we demonstrated that lameness in pregnant sows, especially moderate lameness, has negative effects on the offspring affecting weight gain and increasing number of skin lesions. We also demonstrated altered reactivity during fear tests, indicated by a decreased vocalization in piglets from sows with moderate lameness. Additionally, since there were no differences in cortisol concentration in saliva or placenta tissue, we suggest that other mechanisms, such as cytokines or epigenetics markers, may be involved in the phenotypic outcomes that we demonstrated, and this needs further investigation. Finally, it is worth emphasizing the consequences of ethical concerns to reduce the pain and suffering in lame animals in our care, especially in contexts where effects may pass to the next generation, particularly when we have the knowledge to assess and mitigate this condition in sows.

\section{Data availability}

The datasets generated and analyzed during the current study are available from the corresponding author on reasonable request.

Received: 14 February 2021; Accepted: 8 June 2021

Published online: 22 June 2021

\section{References}

1. Dewey, C. E., Friendship, R. M. \& Wilson, M. R. Clinical and postmortem examination of sows culled for lameness. Can. Vet. J. 34, 555-556 (1993).

2. Heinonen, M. et al. Lameness and fertility of sows and gilts in randomly selected loose-housed herds in Finland. Vet. Rec. 159, 383-387 (2006).

3. Whay, H. R., Main, D. C. J., Green, L. E. \& Webster, A. J. F. Animal-based measures for the assessment of welfare state of dairy cattle, pigs and laying hens: Consensus of expert opinion. Anim. Welf. 12, 205-217 (2003).

4. Pluym, L. M., Maes, D., Van Weyenberg, S. \& Van Nuffel, A. Risk factors for development of lameness in gestating sows within the first days after moving to group housing. Vet. J. 220, 28-33 (2017).

5. van Riet, M. M. J., Millet, S., Aluwé, M. \& Janssens, G. P. J. Impact of nutrition on lameness and claw health in sows. Livest. Sci. 156, 25-35 (2013).

6. Ala-Kurikka, E. et al. Behavior changes associated with lameness in sows. Appl. Anim. Behav. Sci. https://doi.org/10.1016/j.appla nim.2017.03.017 (2016).

7. Bonde, M., Rousing, T., Badsberg, J. H. \& Sørensen, J. T. Associations between lying-down behaviour problems and body condition, limb disorders and skin lesions of lactating sows housed in farrowing crates in commercial sow herds. Livest. Prod. Sci. 87, 179-187 (2004).

8. Grégoire, J., Bergeron, R., D’Allaire, S., Meunier-Salaün, M.-C. \& Devillers, N. Assessment of lameness in sows using gait, footprints, postural behaviour and foot lesion analysis. Animal 7, 1163-1173 (2013).

9. Mohling, C. M. et al. Evaluation of mechanical and thermal nociception as objective tools to measure painful and nonpainful lameness phases in multiparous sows. J. Anim. Sci. 92, 3073-3081 (2014).

10. Ison, S. H., Eddie Clutton, R., Di Giminiani, P. \& Rutherford, K. M. D. A review of pain assessment in pigs. Front. Vet. Sci. 3, 1-16 (2016).

11. Nalon, E., Conte, S., Maes, D., Tuyttens, F. A. M. \& Devillers, N. Assessment of lameness and claw lesions in sows. Livest. Sci. 156, $10-23$ (2013).

12. IASP Task Force on Taxonomy. Part III: Pain terms, a current list with definitions and notes on usage. In Classification of Chronic Pain (eds. Merskey, H. \& Bogduk, N.) 209-214 (IASP Press, 1994).

13. Sneddon, L. U., Elwood, R. W., Adamo, S. A. \& Leach, M. C. Defining and assessing animal pain. Anim. Behav. 97, 201-212 (2014).

14. DeVon, H. A., Piano, M. R., Rosenfeld, A. G. \& Hoppensteadt, D. A. The association of pain with protein inflammatory biomarkers. Nurs. Res. 63, 51-62 (2014).

15. Charil, A., Laplante, D. P., Vaillancourt, C. \& King, S. Prenatal stress and brain development. Brain Res. Rev. 65, 56-79 (2010).

16. Richetto, J. \& Riva, M. A. Prenatal maternal factors in the development of cognitive impairments in the offspring. J. Reprod. Immunol. 104-105, 20-25 (2014).

17. Moisiadis, V. G. \& Matthews, S. G. Glucocorticoids and fetal programming part 1: Outcomes. Nat. Rev. Endocrinol. 10, 403-411 (2014).

18. Seckl, J. R. \& Holmes, M. C. Mechanisms of disease: Glucocorticoids, their placental metabolism and fetal 'programming' of adult pathophysiology. Nat. Clin. Pract. Endocrinol. Metab. 3, 479-488 (2007).

19. Robertson, S. A., Chin, P. Y., Femia, J. G. \& Brown, H. M. Embryotoxic cytokines-Potential roles in embryo loss and fetal programming. J. Reprod. Immunol. 125, 80-88 (2018).

20. Robertson, S. A., Chin, P.-Y., Schjenken, J. E. \& Thompson, J. G. Female tract cytokines and developmental programming in embryos. Adv. Exp. Med. Biol. 843, 173-213 (2015).

21. Almeida, P. E. et al. Gene expression profiling of peripheral mononuclear cells in lame dairy cows with foot lesions. Vet. Immunol. Immunopathol. 120, 234-245 (2007).

22. Sjöblom, C., Roberts, C. T., Wikland, M. \& Robertson, S. A. Granulocyte-macrophage colony-stimulating factor alleviates adverse consequences of embryo culture on fetal growth trajectory and placental morphogenesis. Endocrinology 146, 2142-2153 (2005).

23. Bale, T. L. Epigenetic and transgenerational reprogramming of brain development. Nat. Rev. Neurosci. 16, 332-344 (2015).

24. Hamada, H. \& Matthews, S. G. Prenatal programming of stress responsiveness and behaviours: Progress and perspectives. J. Neuroendocrinol. 31, e12674 (2019).

25. Bernardino, T., Tatemoto, P., Morrone, B., Rodrigues, P. H. M. \& Zanella, A. J. J. Piglets born from sows fed high fibre diets during pregnancy are less aggressive prior to weaning. PLoS ONE 11, 1-11 (2016).

26. Deen, J., Winders, M. \& First", F. Feet First swine locomotion scoring system. https://www.zinpro.com/lameness/swine/locom otion-scoring (2011). Accessed 19 Dec 2020.

27. Main, D. C., Clegg, J., Spatz, A. \& Green, L. E. Repeatability of a lameness scoring system for finishing pigs. Vet. Rec. 147, 574-576 (2000). 
28. Tatemoto, P., Bernardino, T., Rodrigues, F. A. M. L. \& Zanella, A. J. Does high stereotypic behavior expression affect productivity measures in sows? Rev. Bras. Zootec. 48, 1-10 (2019).

29. Guy, J. H., Burns, S. E., Barker, J. M. \& Edwuards, S. A. Reducing post-mixing aggression and skin lesions in weaned pigs by application of a synthetic maternal pheromone. Anim. Welf. 18, 249-255 (2009).

30. Puppe, B., Ernst, K., Schön, P. C. \& Manteuffel, G. Cognitive enrichment affects behavioural reactivity in domestic pigs. Appl. Anim. Behav. Sci. 105, 75-86 (2007).

31. Tatemoto, P., Bernardino, T., Morrone, B., Queiroz, M. R. \& Zanella, A. J. Stereotypic behavior in sows is related to emotionality changes in the offspring. Front. Vet. Sci. 7, 1-7 (2020).

32. Palme, R. \& Möstl, E. Measurement of cortisol metabolites in faeces of sheep as a parameter of cortisol concentration in blood. Int. J. Mammal. Biol. 62(Suppl. 2), 192-197 (1997).

33. Siegford, J. M., Rucker, G. \& Zanella, A. J. Effects of pre-weaning exposure to a maze on stress responses in pigs at weaning and on subsequent performance in spatial and fear-related tests. Appl. Anim. Behav. Sci. 110, 189-202 (2008).

34. Tatemoto, P., Bernardino, T., Alves, L. \& Zanella, A. J. Sham-chewing in sows is associated with decreased fear responses in their offspring. Front. Vet. Sci. 6, 1-9 (2019). https://doi.org/10.3389/fvets.2019.00390.

35. RStudio Team. RStudio: Integrated Development for R. Version: 4.0.5. http://www.rstudio.com/ (2020).

36. Lê, S., Josse, J. \& Husson, F. FactoMineR: An R package for multivariate analysis. J. Stat. Softw. 25, 1-18 (2008).

37. Kassambara, A. \& Mundt, F. Extract and Visualize the Results of Multivariate Data Analyses - Package 'factoextra'. https://CRAN.Rproject.org/package=factoextra (2020). Accessed 27 May 2021.

38. Pohlert, T. Calculate pairwise multiple comparisons of mean rank sums extended - Package 'PMCMRplus'. https://cran.r-project. org/package=PMCMRplus. (2021). Accessed 27 May 2021.

39. Lindsay, R. S., Lindsay, R. M., Edwards, C. R. W. \& Seckl, J. R. Inhibition of $11 \beta$-hydroxysteroid dehydrogenase in pregnant rats and the programming of blood pressure in the offspring. Hypertension 27, 1200-1204 (1996).

40. Mosier, H. D., Dearden, L. C., Jansons, R. A., Roberts, R. C. \& Biggs, C. S. Disproportionate growth of organs and body weight following glucocorticoid treatment of the rat fetus. Dev. Pharmacol. Ther. 4, 89-105 (1982).

41. Novy, M. J. \& Walsh, S. W. Dexamethasone and estradiol treatment in pregnant rhesus macaques: Effects on gestational length, maternal plasma hormones, and fetal growth. Am. J. Obstet. Gynecol. 145, 920-930 (1983).

42. Seckl, J. R. Glucocorticoids and small babies. QJM Int. J. Med. 87, 263 (1994).

43. Peffer, M. E. et al. Minireview: The impact of antenatal therapeutic synthetic glucocorticoids on the developing fetal brain. Mol. Endocrinol. 29, 658-666 (2015).

44. Pluym, L. M., Van Nuffel, A. \& Maes, D. Treatment and prevention of lameness with special emphasis on claw disorders in grouphoused sows. Livest. Sci. 156, 36-43 (2013).

45. Dhama, K. et al. Biomarkers in stress related diseases/disorders: Diagnostic, prognostic, and therapeutic values. Front. Mol. Biosci. 6, 1-50 (2019).

46. Sorensen, N. S. et al. The porcine acute phase protein response to acute clinical and subclinical experimental infection with Streptococcus suis. Vet. Immunol. Immunopathol. 113, 157-168 (2006).

47. Pluym, L. M., Van Nuffel, A., Van Weyenberg, S. \& Maes, D. Prevalence of lameness and claw lesions during different stages in the reproductive cycle of sows and the impact on reproduction results. Animal 7, 1174-1181 (2013).

48. Costermans, N. G. J. et al. Influence of the metabolic state during lactation on milk production in modern sows. Animal 14, 2543-2553 (2020).

49. Strathe, A. V., Bruun, T. S. \& Hansen, C. F. Sows with high milk production had both a high feed intake and high body mobilization. Animal 11, 1913-1921 (2017).

50. Larsen, T., Kaiser, M. \& Herskin, M. S. Does the presence of shoulder ulcers affect the behaviour of sows?. Res. Vet. Sci. 98, 19-24 (2015).

51. Seckl, J. R. Prenatal glucocorticoids and long-term programming. Eur. J. Endocrinol. 151(Suppl), U49-U62 (2004).

52. Kranendonk, G. et al. Lower birth weight and attenuated adrenocortical response to ACTH in offspring from sows that orally received cortisol during gestation. Domest. Anim. Endocrinol. 30, 218-238 (2006).

53. Wyrwoll, C. et al. Fetal brain $11 \beta$-hydroxysteroid dehydrogenase type 2 selectively determines programming of adult depressivelike behaviors and cognitive function, but not anxiety behaviors in male mice. Psychoneuroendocrinology 59, 59-70 (2015).

54. Haussmann, M. F. et al. Administration of ACTH to restrained, pregnant sows alters their pigs' hypothalamic-pituitary-adrenal (HPA) axis. J. Anim. Sci. 78, 2399 (2000).

55. Lau, C. \& Rogers, J. M. Embryonic and fetal programming of physiological disorders in adulthood. Birth. Defects Res. Part C Embryo Today Rev. 72, 300-312 (2004)

56. Hall, S. A. et al. Development and validation of a multiplex fluorescent microsphere immunoassay assay for detection of porcine cytokines. MethodsX 6, 1218-1227 (2019).

57. Poletto, R., Steibel, J. P., Siegford, J. M. \& Zanella, A. J. Effects of early weaning and social isolation on the expression of glucocorticoid and mineralocorticoid receptor and $11 \beta$-hydroxysteroid dehydrogenase 1 and 2 mRNAs in the frontal cortex and hippocampus of piglets. Brain Res. 1067, 36-42 (2006).

58. Yuan, Y., Jansen, J., Charles, D. \& Zanella, A. J. The influence of weaning age on post-mixing agonistic interactions in growing pigs. Appl. Anim. Behav. Sci. 88, 39-46 (2004).

59. Forkman, B., Boissy, A., Meunier-Salaün, M.-C., Canali, E. \& Jones, R. B. A critical review of fear tests used on cattle, pigs, sheep, poultry and horses. Physiol. Behav. 92, 340-374 (2007).

60. Leliveld, L. M. C., Düpjan, S., Tuchscherer, A. \& Puppe, B. Vocal correlates of emotional reactivity within and across contexts in domestic pigs (Sus scrofa). Physiol. Behav. 181, 117-126 (2017).

61. Panksepp, J. \& Burgdorf, J. 'Laughing' rats and the evolutionary antecedents of human joy?. Physiol. Behav. 79, 533-547 (2003).

62. Panksepp, J. \& Burgdorf, J. 50-kHz chirping (laughter?) in response to conditioned and unconditioned tickle-induced reward in rats: Effects of social housing and genetic variables. Behav. Brain Res. 115, 25-38 (2000).

63. Weary, D. M., Braithwaite, L. A. \& Fraser, D. Vocal response to pain in piglets. Appl. Anim. Behav. Sci. 56, 161-172 (1998).

64. Maigrot, A. L., Hillmann, E. \& Briefer, E. F. Encoding of emotional valence in wild boar (Sus scrofa) calls. Animals 8, 1-15 (2018).

65. Weary, D. M., Ross, S. \& Fraser, D. Vocalizations by isolated piglets: A reliable indicator of piglet need directed towards the sow. Appl. Anim. Behav. Sci. 53, 249-257 (1997).

\section{Acknowledgements}

To all students, professors, and staff involved in the University of Sao Paulo. Thanks to FAPESP for the regular FAPESP project (Processo FAPESP number 2018/01082-4), that provided partial funds for the development of this research. Additionally, TB was sponsored by FAPESP with Ph.D. scholarship (Processo FAPESP 2017/056042) during the preparation of this manuscript. To the University of Teramo in Italy by the Ph.D. scholarship granted to MPS during the preparation of this manuscript. The Brazilian pig farm TOPGEN for the supply of the experimental animals, Vedovati Pisos for the donation of the rubber mats used in the experimental work. Dr. Rupert Palme, Unit of Physiology, Pathophysiology and Experimental Endocrinology, Department of Biomedical 
Sciences, University of Veterinary Medicine, Vienna, has donated the reagents for the cortisol EIA. We are grateful to Professor Sandra Edwards and Professor Donald Broom for reviewing the manuscript.

\section{Author contributions}

M.P.S. contributed to the writing of the manuscript, preparation of figures, analysis, and interpretation of data. T.B. contributed to data acquisition, interpretation of data, discussion of results, and preparation of Fig. 1. P.T. contributed to the data acquisition, interpretation of data, and discussion of results. G.P. contributed to the analysis of data, manuscript draft, and preparation of figures. A.J.Z. contributed with the idea conception, design of the work, interpretation of data, and draft of the manuscript. All the authors contributed to the revision of the final version.

\section{Competing interests}

The authors declare no competing interests.

\section{Additional information}

Supplementary Information The online version contains supplementary material available at https://doi.org/ 10.1038/s41598-021-92507-2.

Correspondence and requests for materials should be addressed to M.P.S. or A.J.Z.

Reprints and permissions information is available at www.nature.com/reprints.

Publisher's note Springer Nature remains neutral with regard to jurisdictional claims in published maps and institutional affiliations.

(c) (i) Open Access This article is licensed under a Creative Commons Attribution 4.0 International License, which permits use, sharing, adaptation, distribution and reproduction in any medium or format, as long as you give appropriate credit to the original author(s) and the source, provide a link to the Creative Commons licence, and indicate if changes were made. The images or other third party material in this article are included in the article's Creative Commons licence, unless indicated otherwise in a credit line to the material. If material is not included in the article's Creative Commons licence and your intended use is not permitted by statutory regulation or exceeds the permitted use, you will need to obtain permission directly from the copyright holder. To view a copy of this licence, visit http://creativecommons.org/licenses/by/4.0/.

(C) The Author(s) 2021 